\title{
Üst gastrointestinal sistem kanaması ön tanısı ile refere edilen hastalarda endoskopik aktif kanama oranları
}

Endoscopically active bleeding in patients referred for upper gastrointestinal bleeding (Active bleeding rates in patients with symptoms)

Irfan KORUK, Hakan ÇAM, Musa AYDINLI, Nimet YILMAZ, M. Sait DAĞ, Umut DEMİR, Ayhan BALKAN

Gaziantep Universitesi Tip Fakültesi Gastroenteroloji Bilim Dall, Gaziantep

Giriş ve Amaç: Üst gastrointestinal sistem kanamaları Gastroenterolojinin önemli uğraş alanlarından birini oluşturmaktadır. Bu hastalarda ön klinik değerlendirme en önemli basamaklardan birini oluşturmaktadır. Bazı hastalar gastrointestinal sistem kanama ön tanısı ile gönderilmelerine rağmen aktif kanama izlenmemektedir. Bu çalışmada, üst gastrointestinal sistem kanaması tanısı ile merkezimize refere edilen hastalardan aktif kanamalı hastalar ve bunların endoskopi bulguları değerlendirildi. Gereç ve Yöntem: Toplam 20 aylık bir sürede kliniğimiz endoskopi ünitesine üst gastrointestinal sistem kanama ön tanısı ile refere edilen hastalar çalışmaya dahil edildi. Bu hastaların endoskopi bulguları ve aktif kanama oranları kaydedildi. Veriler retrospektif olarak değerlendirildi. Bulgular: Bu süre içerisinde toplam 13661 üst gastrointestinal sistem endoskopisi yapılmıştır. Bunların 951 tanesine (\%7) üst gastrointestinal sistem kanama ön tanısı ile erken endoskopik işlem yapılmıştır. 232 hastada $(\% 24,4)$ aktif kanamalı lezyon tespit edilmiştir. Bu hastaların 120 tanesinde (\%52) duodenal ülser, 67 hastada (\%29) gastrik ülser, 29 hastada (\%12) özofagus varisi, 16 hastada (\%7) eroziv gastropati-bulbopati saptanmıştır. Hastaların 719'unda $(\% 75,6)$ ise endoskopide tespit edilen aktif kanama yoktu. Sonuç: Erken dönemde yapılan endoskopilerin çoğunda aktif kanama olmaması, klinik olarak hastaların daha dikkatli degerlendirilmesi ve acil endoskopi gereken hastaların iyi belirlenmesi gerekliliğini göstermektedir. Bu ise hem işgücünün aktif ve verimli kullanılması hem de hastaların tedavi yönlendirilmesinde önem teşkil etmektedir.

Anahtar Kelimeler: Ust gastrointestinal sistem kanama, aktif kanama, klinik değerlendirme

\section{GİISS}

Üst gastrointestinal sistem (GIS) kanaması gastroenterolojinin en sık karşılaşılan sorunlarındandır. Şiddeti; gizli kanamadan, abondan kanamaya kadar değişebilir. Hastalar kronik anemi veya hipovolemik şok bulguları ile karşımıza çıkabilir. Acil tedavi için hangi hastanın daha öncelikli olduğu ortaya konmalıdır. Erken endoskopi gereken hastalar mümkün olduğunca kısa sürede işleme alınmalıdır. Klinik olarak aktif üst GIS kanama düşünülen hastalarda tanıyı doğrulamak ve tedaviyi yönlendirmek için yapılan üst GİS endoskopisi altın standarttır (1). Ancak endoskopinin zamanlaması ve endoskopi sonrası elde edilen bulguların değerlendirilmesi ile bu hastalarda öncelikli olan ön değerlendirmenin tam yapılıp yapılmadığı önem arz etmektedir. Bu çalışmada üst GİS kanama ön tanısı ile endoskopiye refere edilen hastalardan aktif kanamalı hastalar ve bunların endoskopi bulguları değerlendirildi.
Background and Aims: Upper gastrointestinal system bleeding is a major topic in gastroenterology practice. The clinical evaluation is important for the timing of the endoscopy and to determine whether active bleeding exists or not in these patients. Active bleeding goes unnoticed on endoscopy in some patients. The aim of this study was to evaluate the endoscopic findings and active bleeding rates of patients who were referred to the endoscopy unit with a diagnosis of upper gastrointestinal system bleeding. Materials and Methods: The patients referred to the endoscopy unit with a diagnosis of active upper gastrointestinal system bleeding were enrolled into the study for a 20-month period. The endoscopic findings and active bleeding rates were recorded. The variables were retrospectively evaluated. Results: In the study period (20 months), a total of 13661 upper gastrointestinal system endoscopies were done. 951 of them (7\%) applied for a clinical diagnosis of gastrointestinal system bleeding. Active bleeding was seen in 232 patients (24.4\%). Of 232 patients with active bleeding, 120 (52\%) had duodenal ulcer, 67 (29\%) had gastric ulcer, 29 (12\%) had esophageal varices, and 16 (7\%) had erosive gastro-bulbopathy. In $719 / 951$ patients (75.6\%), there was no sign of active bleeding during endoscopy. Conclusions: In this study, it was shown that in three-fourths of patients with suspected upper gastrointestinal system bleeding, no active bleeding was shown on endoscopy. Therefore, physicians must be more attentive during the pre-endoscopic clinical evaluation.

Keywords: Upper gastrointestinal system bleeding, active bleeding, clinical evaluation

\section{GEREC ve YÖNTEM}

Bu çalışmaya toplam 20 aylık sürede Gaziantep Üniversitesi Tıp Fakültesi Gastroenteroloji Bilim Dalı Endoskopi Ünitesi'ne poliklinikten veya acil servisten üst GIS kanama ön tanısı ile endoskopi yapılmak üzere yönlendirilen hastalar alındı. $\mathrm{Bu}$ hastaların verileri dosyalar üzerinden retrospektif olarak tarandı. Bu hastalar arasından acile veya polikliniğe başvuruşundan sonraki ilk 24 saat içinde üst GíS endoskopisi (erken endoskopi) yapılan hastalar çalışmaya dahil edilerek sonuçları takip edildi. Klinikte, ileri yaştaki hastalar, aktif hematemezi olanlar, takipte hematokrit değerlerinde progresif düşüş olanlar, özofagus varis kanaması ön tanısı olan hastalar öncelikli olarak erken dönemde (ilk 24 saat içerisinde) endoskopiye alınmaktadır. Hastaların endoskopi sonuçları, aktif kanama oranı ve tespit edilen patolojiler kaydedildi. 


$\begin{array}{lcccc}\text { Tablo 1. Kanama nedenleri ve demografik özellikleri } & & & \\ \text { Saptanan Lezyon } & \text { Olgu Sayısı } & \text { Erkek } & \text { Kadın } & \text { Yaş (median) } \\ \text { Duodenum ülseri } & 120(\% 52) & 55(\% 78.5) & 15(\% 21.5) & 64 \\ \text { Gastrik ülser } & 67(\% 29) & 24(\% 58.6) & 17(\% 41.4) & 61 \\ \text { Özofagus varisi } & 29(\% 12) & 12(\% 70.5) & 5(\% 29.5) & 55 \\ \text { Eroziv gastrit + bulbit } & 16(\% 7) & 7(\% 58.3) & 5(\% 41.7) & 48\end{array}$

\section{BULGULAR}

Belirtilen tarihler arasında toplam 13661 üst GIS endoskopisi yapılmıştır. Bunların 951 tanesine (\%7) üst GIS kanama ön tanısı ile erken endoskopik işlem yapılmıştır. Bu hastaların sonuçları kaydedilmiştir. Üst GIS'inde kanama ön tanısı ile yapilan 951 endoskopinin 232 tanesinde $(\% 24,4)$ endoskopide aktif kanamalı lezyon tespit edilmiştir (Şekil 1). Bu hastaların 120 tanesinde (\%52) duodenal ülser, 67'sinde (\%29) gastrik ülser, 29'unda (\%12) özofagus varisi, 16'sında (\%7) eroziv gastropati-bulbopati tespit edilmiştir (Şekil 2). Aktif kanamalı hastaların demografik özellikleri Tablo l'de ve lezyonların Forrest sınıflaması Tablo 2'de belirtilmiştir. Erkekler bütün gruplarda kanamalı hastaların çoğunluğunu oluşturuyordu. Özellikle duodenal ülser (3.6/1) ve özofagus varis ka-

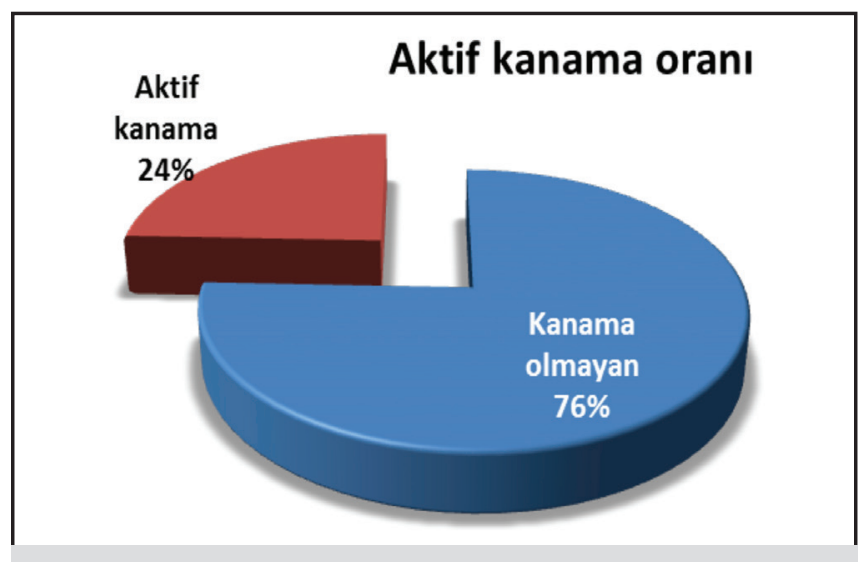

Şekil 1. Aktif kanama oranları

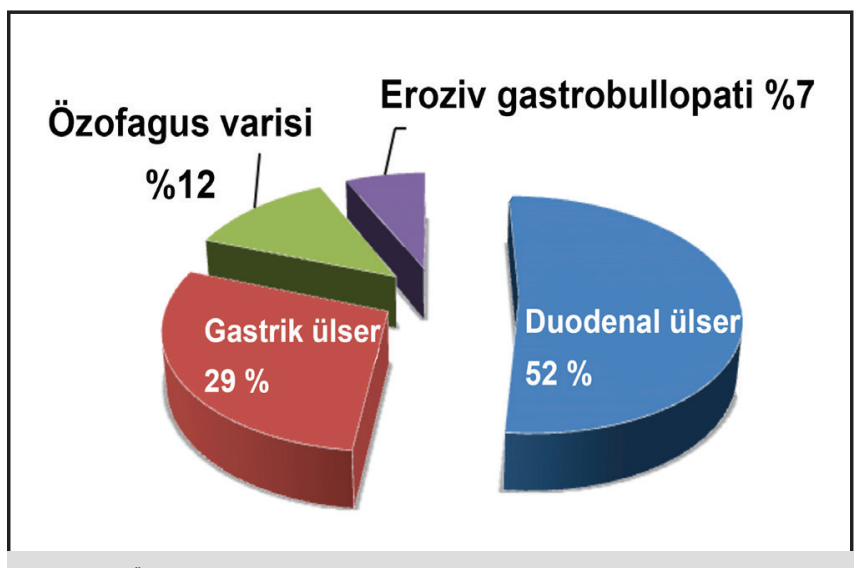

Şekil 2. Üst GIS kanama nedenleri namasında (2.4/1) sayı olarak erkek üstünlüğü belirgindi. Yaş ortalaması olarak en genç grup 48 yaş ile eroziv gastrit-bulbit iken en yaşlı grup 64 yaş ile duodenal ülser grubuydu. Anatomik olarak ise duodenal ülserlerin \%90'ı bulbusta, \%10'u duodenum 2. ve 3. kisminda izlendi. Gastrik ülserler ise \%70 antrum, \%16 korpus, \%10 fundus ve \%4 kardiyada yerleşmişti. Üst GIS kanama ön tanısı ile yapılan endoskopilerin ortalama işleme alınma süreleri 4,5 (range: 0,5-24) saat idi. Hastaların 719 'unda $(\% 75,6)$ endoskopide tespit edilen aktif kanama yoktu.

\section{TARTISSMA}

Üst GIS kanama sık karşılaşılan ve önemli GIS acillerinden birisidir. Tüm gelişmelere rağmen mortalite \%10 olarak devam etmektedir (2). Bu hastalarda üst GIS endoskopi hem tanı hem de tedavi için altın standart yöntemdir (1). Endoskopik tedavinin etkili ve zamanında yapılmasının mortalite ve morbiditeyi azalttığı gösterilmiştir (3). Bununla birlikte hangi hastaya acil endoskopi yapılması gerektiği iyi bilinmelidir. Bu çalışmada acil servis veya polikliniğe müracaat eden ve klinik değerlendirme ile GIS kanama düşünülen hastalara endoskopi yapılmıştır.

Üst GIS kanamasının tanısında anamnez ve fizik muayene bulgularının değerlendirilmesi çok önemlidir. Bu sayede kanayan hastaya zamanında müdahale edilebileceği gibi gereksiz işlemlerin de önüne geçilecektir.

Demir, bizmut, multivitamin içeren preparatların gaita rengini siyah yapabileceği unutulmamalıdır (4). Kanama durduktan sonra 1-3 gün melena şeklinde dışkılama devam eder. Gaitada gizli kan pozitifliği 3 haftaya kadar uzayabilir. Hematemez olması yüksek ihtimalle üst GİS kanamasını gösterirken, olmaması ise kanamayı ekarte ettirmez. Nazogastrik sondaya safralı sıvı gelmesi büyük ölçüde üst GIS kanamayı ekarte ettirir (4). Yoğun üst GIS kanamasında kan sindirilmeden rektuma ulaşıp hematokezya şeklinde görülebilir. Bu nedenle aşırı hematokezya ile müracaat eden hastaların \%10 kadarında kanama nedeni alt değil, üst gastrointestinal kanaldadir (4).

Total kan hacminin \%10'unu kaybeden hastada vagal senkop görülebilir. Yüzde 20 kayıpta efor sonrası taşikardi, \%30 kayıpta ayağa kalkınca hipotansiyon, \%40 kayıpta sırtüstü ya- 


$\begin{array}{lcccc}\text { Tablo 2. Lezyonların Forrest siniflamasına göre dağllımı } & & & \\ \text { Lezyon } & \text { Forrest la } & \text { Forrest } \mathbf{l b} & \text { Forrest 2a } & \text { Forrest 2b } \\ \text { Duodenum ülseri } & 10 & 23 & 19 & 18 \\ \text { Mide ülseri } & 3 & 12 & 18 & 8\end{array}$

tarken hipotansiyon ve taşikardi, \%50 kayıpta ise ciddi şok ve ölüm görülür. Genel bir kural olarak; sistolik kan basıncı 100 mmHg'nin altında ve nabız dakika sayısı 100 atım/dk'dan fazla ise volüm kaybı \%20'den fazladır. Tilt testinin pozitif olması da \%20'den fazla volüm kaybına işaret eder (5).

Kliniğimize üst GİS kanama ile başvuran hastalara ortalama endoskopi yapılma zamanı 4,5 saat olarak gerçekleşmiştir. Üst GIS kanamalarında tedavi başarısını etkileyen faktörlerden birisi de klinik prezentasyonla endoskopi arasında geçen süredir (6). Okutur ve arkadaşlarının yaptığı çalışmada erken endoskopi yapılan ve yapılmayan hastalar karşılaştırılmıştır. Erken endoskopi gerektiren olguların yaşları daha ileri, hemoglobin düzeyi daha düşük saptanmıştır. Fakat ölüm oranları arasında anlamlı bir farklılık görülmemiştir (6). Günay ve arkadaşlarının yaptığı merkezimize ait prospektif bir çalışmada hastaların acil servise başvurması ile endoskopiye alınması arasında geçen süre ortalama 4,6 saat olarak belirlenmiştir (7). Söz konusu çalışmada erken endoskopi ile hastanede kalma süresi ve mortalite oranının düştügü saptanmıştır. Birçok çalışma da özellikle risk grupları için erken endoskopik yaklaşımı desteklemektedir $(8,9)$. Bu nedenle, özellikle yüksek risk grubunda bulunan hastalara mümkün olan en kısa zamanda endoskopi uygulanmalıdır. Kliniğimizde 24 saat acil endoskopi yapılabilmekte olup özellikle ileri yaş, önemli ek hastalığı olan, hematemez ile başvuran, varis kanaması düşünülen ve takiplerinde progresif hemoglobin düşüklügü olan hastalara, ilk 24 saat içerisinde, en kısa zamanda endoskopi işlemi yapılabilmektedir.

Bilindiği üzere nüks kanama da mortalite ile ilişkili bulunmuştur (10). Yine başka bir çalışmada 65 yaş üzeri olmak, yandaş hastalık varlığı, geliş hemoglobin düzeyinin düşük olması, mide lavajında taze kan bulunması ve hematemez nüks kanama ile anlamlı düzeyde ilişkili bulunmuştur (11).

Ateş ve arkadaşlarının yaptığı bir çalışmada da 60 yaş üzeri olmak ve/veya yandaş hastalığa sahip olmak mortalite için anlamlı risk faktörleri olarak saptanmıştır (12). Aynı çalışmada erkek cinsiyet, sigara, nonsteroid antiinflamatuvar ilaç (NSAIi), antikoagülan ilaçlarla mortalite arasında ilişki saptanmamıştır. NSAII'ın özellikle yaşlılarda üst GIS kanama riskini arttırdığı gösterilmiştir (13). Başka bir çalışmada yaşı ileri ve yandaş hastalığı olan hastaların semptomatik olmasalar bile mortalite oranının daha yüksek olduğu saptanmıştır (14). Yaşlı ve yandaş hastalığı olanlar için cerrahi girişim oldukça risklidir. Genellikle hipovolemiyi de tolere edemezler. Bu nedenle ivedilikle ve uygun bir endoskopik işlemle kanamalarının durdurulması gerekmektedir.

Kliniğimizde üst GIS kanama nedenlerine bakıldığında en sık nedenin duodenal ülser olduğu görülmüştür (\%52). Daha sonra azalan sırayla gastrik ülser, varis kanaması, eroziv gastropati-bulbopati saptanmıştır (\%29, \%12, \%7). Ülkemizde yapılan diğer çalışmalarda da genellikle benzer sonuçlar elde edilmiştir $(15,16)$. Varis kanamaları ülser kanamalarına göre daha ağır seyretmektedir (17). Ayrıca varis kanamalarında nüks kanama daha fazla görülmektedir (18). Ilk kanamadan sonraki 5 gün nüks kanama için en riskli günlerdir. Varis kanaması bu yönlerden yakın takip edilmelidir. Ülser kanamalarında da nüks kanamalarının önlenmesi adına mümkün olduğunca kombine endoskopik tedavi düşünülmelidir (19).

Bizim çalışmamızda acil servis veya polikliniğe üst GIS kanama bulguları ile müracaat eden hastalarda ilk 24 saat içerisinde uygulanan endoskopinin sonuçları ve bu hastaların ne kadarında endoskopik olarak aktif kanama olup olmadığ araştırıldı. Hastaların sadece \%24,4'ünde endoskopik olarak aktif kanama tespit edilmiştir. Erken dönemde yapılan endoskopilerin \%75,6'sinde aktif kanama olmaması, klinik olarak hastaların daha dikkatli değerlendirilmesi ve acil endoskopi gereken hastaların iyi tespiti gerekliliğini göstermektedir. Bu ise hem işgücünün aktif ve verimli kullanılması hem de hastaların tedavi yönlendirilmesinde önem teşkil etmektedir.

Üst GİS kanaması düşünülen hasta ile karşılaşıldığında veriler iyi bir şekilde ortaya konmalı, klinik ve laboratuvar değerlendirme ile erken endoskopik işlem gereken hastalar belirlenmelidir. Farmakolojik tedavi ve gerekirse transfüzyonla hastanın hemodinamisi desteklenmelidir. Özellikle mortalite ve nüks kanama açısından yüksek risk göstergeleri bulunan hastalara mümkün olan en kısa zamanda endoskopi yapılmalıdır. Böylece mortalitesi yüksek olan cerrahi bir girişimin önüne geçilebileceği gibi, zaman ve enerji kaybı da en aza indirilmiş olacaktır. 


\section{KAYNAKLAR}

1. Arasaradnam RP, Donnelly MT. Acute endoscopic intervention in non variceal upper gastrointestinalbleeding. Postgrad Med J 2005;81:92-8

2. Rolihauser C, Fleischer DE. Nonvariceal upper gastrointestinal bleeding Endoscopy 2004;36:52-8.

3. Cook DJ, Guyatt GH, Salena BJ, Laine LA. Endoscopic therapy for acute nonvariceal upper gastrointestinal hemorrhage: a meta-analysis. Gastroenterology 1992;102:139-48.

4. Iliçin G, Biberoğlu K, Süleymanlar G, Ünal S. Iç Hastalıkları, Güneş Kitabevi. 2. Baskı: 2005 Cilt 1, Bölüm 9: 1661-62.

5. Çalangu S, Güler K. Acil Dahiliye. 5. Baskı. Istanbul Tıp Fakültesi Kitaplığı. 1997;319-20.

6. Okutur SK, Alkım C, Bes C, et al. Akut üst gastrointestinal sistem kanamaları: 230 olgunun analizi. Akademik Gastroenteroloji Dergisi 2007;6:30-6.

7. Günay N, Yıldırım C, Sezgin S, et al. Acil servise başvuran üst gastrointestinal sistem kanamalı hastalar için bazı zaman değerlerinin prospektif olarak saptanması. Akademik Acil Tıp Dergisi 2006;4:17-20.

8. Longstreth GF, Feitelberg SP. Successful outpatient management of acute upper gastrointestinal hemorrhage: use of practice guidelines in a large patient series. Gastrointest Endosc 1998;47:219-22.

9. Cooper GS, Chak A, Connors AF Jr, et al. The effectiveness of early endoscopy for upper gastrointestinal hemorrhage: a community-based analysis. Med Care 1998;36:462-74.

10. Guglielmi A, Ruzzenente A, Sandri M, et al. Risk assessment and prediction of rebleeding in bleeding gastroduodenal ulcer. Endoscopy 2002;34:778-86.
11. Barkun A, Bardou M, Marshall JK. Nonvariceal Upper GI Bleeding Consensus Conference Group. Consensus recommendations for managing patients with nonvariceal upper gastrointestinal bleeding. Ann Intern Med 2003;139:843-57.

12. Ateş F, Karıncaoğlu M, Aladağ M. Varis dışı üst gastrointestinal sistem kanamalı 524 olgunun değerlendirilmesi. Inönü Üniversitesi Tıp Fakültesi Dergisi, 2008;15:93-8.

13. Küçükardalı Y, Yazgan Y, Çankır Z, et al. Geriatrik popülasyonda nonsteroidal antiinflamatuar ilaçlara bağlı olan ve olmayan üst gastrointestinal sistem kanamalı olguların karşılaştırılması. Turkish Journal of Geriatrics 2002;5:87-90.

14. Kaplan RC, Hecbert SR, Psaty BM. Risk factors for hospitalized upper or lower gastrointestinal tract bleeding intreated hypertensives. Prev Med 2002;34:455-62

15. Yenigün EC, Pirpir A, Aytan P, Ulusal G, et al. Üst gastrointestinal sistem kanamalı hastaların özelliklerinin değerlendirilmesi. Akademik Gastroenteroloji Dergisi 2006;5:116-22.

16. Aksöz K, Ünsal B, Akyol Z. Üst gastrointestinal kanamalı 2568 hastanın değerlendirilmesi. Turk J Gastroenterol 1995;6:262-4.

17. Bjorkman D. GI hemorrhage and occult GI bleeding. In: Goldman L, Ausiello D. Cecil Textbook of Medicine. 22nd ed. Philadelphia, Pa: Saunders Elsevier; 2004:chap 133.

18. Yücesoy M, Baskol M, Keklik M, et al. Efficacy of five days of subcutaneous octreotide treatment after sclerotherapy in preventing rebleeding from esophageal varices. Turk J Gastroenterol 2004;15:137-43.

19. Oh DS, Pisegna JR. Management of upper gastrointestinal bleeding. Clin Fam Pract 2004;6:631-45. 